\title{
Effect of processing parameters on copper powder produced by novel hybrid atomisation technique
}

Sasha Alejandra Cegarra Salges ${ }^{1 *}$, Jordi Pijuan ${ }^{1}$, Ricardo Hernández ${ }^{1}$, Maria Dolores Riera ${ }^{2}$

1 Department of Processing Modelling and Simulation, Technological Centre EURECAT, Manresa, Spain

2 Department of Mining, Industrial and ICT Engineering, Technical University of Catalonia-(UPC), Manresa, Spain

*Technological centre EURECAT, Plaça de la Ciencia, 2, 08242, Manresa, Spain. *sasha.cegarra@eurecat.org

\section{ORCiDs}

Sasha Alejandra Cegarra: 0000-0002-4675-9931

Jordi Pijuan: $\underline{0000-0002-9498-0673}$

María Dolores Riera: 0000-0001-9733-416X 


\title{
Effect of processing parameters on copper powder produced by novel hybrid atomisation technique
}

\begin{abstract}
In the present work, a novel design of centrifugal atomiser for producing pure copper powder was studied. The novel complementary hybrid system provides an external stream of gas to increase the cooling rate of the atomised particles. Effects of the operating parameters, such as disc rotating speed and gas flowrate on the morphology, particle size distribution, cooling rate and microstructure, were analysed. It was evidenced from the experimental results that the median particle size in the novel atomisation process is mainly controlled by centrifugal disintegration. The microstructure of the produced powders was equiaxed and the grain size decreased with increasing gas flowrate. The cooling rate experienced by centrifugal atomised $\mathrm{Cu}$ powders were studied via numerical formulation estimated to be $10^{4}-10^{6} \mathrm{~K} / \mathrm{s}$. The results show that the cooling rate is a strong function of particle size and increasing the rotating disc speed also increased the cooling rates.
\end{abstract}

Keywords: centrifugal atomisation; complementary hybrid system; cooling rate; microstructure; metal powder.

\section{INTRODUCTION}

Centrifugal atomisation of melt has been used for metal powder production for decades [1-3]. This process is able to produce spherical particles, with less impurity and narrow size distribution at a low production cost in terms of energy consumption [4]. Centrifugal atomization is considered a Rapid Solidification Process (RSP) which involves high rates of cooling during solidification $\left(10^{4}-10^{6} \mathrm{~K} \mathrm{~s}^{-1}\right)$ [5]. During this process, raw materials are melted in an inert gas atmosphere. The liquid metal stream is ejected onto a high speed rotating disc which breaks up the liquid into a spray of droplets, which solidify in flight to form powder. Depending on the atomisation parameters, particles are produced either by direct drop formation, by ligament disintegration or by film disintegration from the disc edge [6]. At a low volumetric 
flowrate and low disc speed, direct droplet formation is observed at the edge of the disc. With increasing volumetric flowrate and disc speed, ligament disintegration is the main mode of flow behaviour. Film disintegration appears at even higher flowrates and disc speeds and the surface of the atomising is covered by a continuous film moving from the centre to the periphery of the disc. The particle diameter has been predicted using the equation [7]:

$$
d_{50}=\sqrt{\frac{6 \sigma}{\rho \omega^{2} R}}
$$

Where $\sigma$ is the surface tension $\left(\mathrm{N} \mathrm{m}^{-1}\right), \rho$ is the density $\left(\mathrm{Kg} \mathrm{m}^{-3}\right), \omega$ is the angular velocity $\left(\operatorname{rad~s}^{-1}\right)$ and $\mathrm{R}$ is the atomiser disc radius $(\mathrm{m})$. This equation implies that increasing angular speed will result in smaller particle size.

The present work aims to investigate the influence of operating parameters on the new atomisation process. This study reports the effects of the gas flowrate and rotational speed on the median particle size, microstructure and cooling rate of pure copper powder, produced by the novel hybrid atomisation system.

\section{BASIC PRINCIPLE}

A new complementary hybrid system has been added to the centrifugal atomisation equipment in order to increase the cooling rate of the atomised particles. The high rates of cooling could lead to significant modifications on microstructures. The advantage of this technique is to be able to design new metal powders of alloys beyond the equilibrium. Centrifugal atomization gives coarse mean powder sizes $(>45 \mu \mathrm{m})$ that do not meet the requirements for various advanced powder metallurgy manufacturing technologies [8]. Thus, a new way has been thought to promote a high cooling rate and a further breakup of the droplets. 
The hybrid atomisation process described in this study is the improvement of a conventional centrifugal atomiser with the addition of an external stream of gas at the periphery of the disc. This technique consists of two steps in the following order: the disintegration of the molten metal into fine particles through centrifugal atomisation followed by rapid solidification of these particles through the hybrid gas system. The advantages of this specific design is that the feed material is first spread out by a spinning disc due to centrifugal forces, and once atomised, the droplets are rapidly cooled by a stream of gas. The combination of both techniques lead to high cooling rates that promotes modifications on the material microstructure which results in high quality powder with an increasing demand as new technology emerge that can make use of their unique characteristics. Although this process is called "hybrid atomisation system", it is only to remark the combination of two techniques. The concept behind it is different than others hybrid systems documented in the literature [9].

\section{EXPERIMENT PROCEDURES}

The centrifugal spinning disc unit with the hybrid complementary system is shown in figure 1. This equipment contains four parts: The atomisation chamber, the induction melting system with crucible, the spinning disc with the hybrid system and the vacuum and inert gas system.

Figure 1. Schematic diagram of the centrifugal atomisation equipment with the hybrid complementary system.

Electrolytic copper with purity of $99,9 \%$ was used as a starting raw material. The $\mathrm{Cu}$ was induction melted in a crucible. The melt stream flowed through a nozzle under gravity onto the atomisation disc, atomising the melt stream. 
The main processing parameters for this study were the disc speed of atomisation and the gas flowrate from the hybrid system. A set of test runs were carried out with the variation ranges of the main parameters as shown in table (1). $1 \mathrm{Kg}$ of Cu was melted for each experiment. In any group of experiments, only one parameter was varied with the others being fixed.

Table 1 Processing experimental parameters of atomisation

After each atomisation, each of the as produced powders was sieved and weighed. However, due to a large concentration of flakes and splats, all particles larger than $355 \mu \mathrm{m}$ were discounted, corresponding to approximately $35 \%$ of the atomised material. The sampled powder was loaded onto a series of sieves and shaken on a sieve shaker for $15 \mathrm{~min}$. The powder weight retained on each sieve was determined. The sieve data were plotted on a log-normal plot to evaluate its particle size distribution and median particle size. The samples were selected and they were mounted in cold resin and metallographically prepared for microstructural examinations. The samples were polished and etched using a reagent, with the composition of $100 \mathrm{~mL} \mathrm{H}_{2} \mathrm{O}-100 \mathrm{~mL}$ $\mathrm{C}_{2} \mathrm{H}_{5} \mathrm{OH}-19 \mathrm{gr} \mathrm{Fe}\left(\mathrm{NO}_{3}\right)_{3}$. The morphology of the atomized particles was observed by using Ultra Plus Field Emission Scanning Electron Microscope (SEM). The microstructure and average grain sizes of powders were analysed with a Nikon Epiphot 200 optical microscope. Due to the lack of a standard test method to determine the average grain size in metal powders, the criteria used in this study was to measure the mean grain size area in 5 different micrographs for each sample from each atomisation. 


\section{RESULTS AND DISCUSSION}

\section{Particle size distribution}

Figure $2 \mathrm{a}$ show the particle size distribution of copper metal powders produced by centrifugal atomisation for different hybrid gas flowrates at a constant disc speed of $25000 \mathrm{rpm}$. It can readily be seen that the gas flowrate does not affect the particle size distribution significantly lacking a clear tendency and having a median particle size (dm) from $72 \mu \mathrm{m}$ to $76,9 \mu \mathrm{m}$ with a standard deviation of $1,61-1,67$. As opposed to figure $2 \mathrm{a}$, figure $2 \mathrm{~b}$ demonstrates that the particle size distribution of the $\mathrm{Cu}$ powder tends to be finer with increasing rotational disc speed with a median particle size range between $68,1 \mu \mathrm{m}-88,3 \mu \mathrm{m}$ and a standard deviation of 1,53-1,75 [7,10,11].

It is also observed from figure 3 that the median particle size of produced copper powder decreases with increasing rotational disc speed, with similar values for conventional centrifugal atomisation and hybrid atomisation Thus, the final particle size obtained using the hybrid atomisation system is mainly controlled by the centrifugal disintegration. The medium particle size of produced copper powder from the present study is smaller than that predicted by equation (1). Thus the results imply little slippage of melt on the surface of the atomising disc, a consequence of an excellent wetting between melt and the graphite disc surface.

Figure 2. Particle size distribution of copper powder at (a) different hybrid gas flowrate and a rotating disc speed $25000 \mathrm{rpm}$ and (b) different rotating speed and gas flowrate $200 \mathrm{~L} \mathrm{~min}^{-1}$.

Figure 3. Effect of rotating disc speed on median particle at different hybrid gas flowrates. 


\section{Morphology of Cu powder}

SEM micrographs in figure 4 reveal the morphology of the $\mathrm{Cu}$ powder for conventional centrifugal atomisation and with the hybrid complementary system. As illustrated in the same figure, the morphology of these powders is spherical or nearly spherical. In addition, few satellites are found around main particles under both atomisation conditions and no hollow particles were detected.

Figure 4. SEM images of $\mathrm{Cu}$ powders by hybrid atomisation at $200 \mathrm{~L} \mathrm{~min}-1$ (a,b,c) and centrifugal atomisation $(\mathrm{d}, \mathrm{e}, \mathrm{f})$ at $35000 \mathrm{rpm}$ for different particle size: $(\mathrm{a}, \mathrm{d}) \mathbf{1 0 6}-75 \mu \mathrm{m}$, (b,e) 75-45 $\mu \mathrm{m},(\mathrm{c}, \mathrm{f}) 45-20 \mu \mathrm{m}$.

\section{Grain size as a function of gas flowrate}

The microstructure of atomised particles for both conventional and hybrid atomisation was equiaxed and mainly affected by the particle size. The mean grain size area of the particles decreased with decreasing particles size. This was due to smaller surface area/volume ratios and a higher heat content of the large particles, which resulted in lower cooling rate and larger microstructure [12].

Micrographs from figure 5 show that the particle grain size is highly variable, which indicates the complexity of the process even in the same range of particle size. If considering spherical grains that nucleate randomly in a given particle, as the grains grow, they will eventually impinge on one another determining the variability of the grain sizes, even within the same range of grain size. These effects are explained on the basis of competing nucleation and growth phenomena during solidification of the atomised particles [12]. Within this process is mandatory to add the complexity of the particle break up from the melt, particle trajectory and particle velocity. Nonetheless, according to the literature and as shown in this study, higher cooling rate will result in a decrease in grain size [12]. 
Figure 5. MO images of $\mathrm{Cu}$ powders by hybrid atomization: (a-b) 106-75 $\mu \mathrm{m}$.

According to figure 6, when the gas flowrate increases from 0 to $200 \mathrm{~L} \mathrm{~min}^{-1}$, the mean grain size of the particle decreases, having the same tendency for different speeds of atomization. As can be seen from the figures, the effect of gas flowrate is stronger at lower disc rotational speeds. At $15000 \mathrm{rpm}$ the average grain size was reduced by half for $106 \mu \mathrm{m}$ particles. This can be explained in terms of disc-particle dynamics. At lower speeds, the velocity of the droplet at the edge of the disc is lower, accounting for a higher contribution of the hybrid vertical component. However, the gas flowrate implemented in this study has no effect on the particle size distribution as discussed previously. These results confirm that the grain size has a stronger dependence on the cooling rate relative to that of particle size [13].

A finer microstructure is a consequence of higher cooling rates. Thus, from the results the cooling rate is expected to increase with increasing hybridisation gas flowrate at a constant disc speed and with increasing disc speed at a constant gas flowrate. However, experimentally the effect of disc speed on grain size was not evident.

Figure 6. Grain size area as a function of gas flowrate at different speeds of atomization: (a) $35000 \mathrm{rpm}$, (b) $25000 \mathrm{rpm}$ and (c) $15000 \mathrm{rpm}$.

\section{Cooling rate analysis}

The cooling rate process of the atomised particles were theoretically calculated assuming the concept of a single particle which is projected into a gas flow in the same direction as the velocity of the particle. The complexities of the system require additional assumptions [4] reported below.

For conventional centrifugal atomization, the initial droplet velocity is assumed to be the peripheral tangential velocity of the disc. When using the hybrid 
complementary system, the vertical component velocity is also taken into account.

Therefore, the total droplet velocity increases and the convection heat transfer coefficient is higher.

According to Yule and Dunkley [4], after the droplet is completely solidified, it furthers cools down in the solid state. This process can be evaluated from the sum of heat convection $(\mathrm{Qc})$ and heat radiation $(\mathrm{Qr})$ using the following equation:

$$
Q_{\text {ave }}=A_{s} h\left(T_{d}-T_{A}\right)+A_{s} \varepsilon S_{T}\left(T_{d}^{4}-T_{A}^{4}\right)
$$

Where $\mathrm{h}$ is the convection heat transfer coefficient $\left(\mathrm{W} \cdot \mathrm{m}^{-2} \cdot \mathrm{K}^{-1}\right), \mathrm{A}_{\mathrm{s}}$ is the total surface area of sphere particle $\left(\mathrm{m}^{2}\right), \varepsilon$ is the emissivity $\left(0,52\right.$, according to [4]), $\mathrm{S}_{\mathrm{T}}$ is the Stefan-Boltzmann constant $\left(5,67 \times 10^{-8} \mathrm{~W} \cdot \mathrm{m}^{-2} \cdot \mathrm{K}^{-4}\right), \mathrm{T}_{\mathrm{d}}$ is the temperature of the droplet $(\mathrm{K})$ and $\mathrm{T}_{\mathrm{A}}$ is the ambient temperature of the atomization chamber.

Fuqian et al. [14] evaluates the convection heat transfer coefficient in terms of the relationship between Reynolds Number $(\mathrm{Re})$, the Nusselt number $(\mathrm{Nu})$ and Prandtl number (Pr):

$$
h=\frac{K_{g}}{d}\left[2+0,6\left(\frac{V_{d} \rho_{g} d}{\eta_{g}}\right)^{1 / 2}\left(\frac{c_{g} \eta_{g}}{K_{g}}\right)^{1 / 3}\right]
$$

Where $\mathrm{K}_{\mathrm{g}}$ is the thermal conductivity of gas $\left(\mathrm{W} \mathrm{m}^{-1} \mathrm{~K}^{-1}\right)$, $\mathrm{d}$ the diameter of a droplet $(\mathrm{m}), \mathrm{V}_{\mathrm{d}}$ the relative velocity of the droplet $\left(\mathrm{m} \mathrm{s}^{-1}\right), \rho_{\mathrm{g}}$ the density of the gas $\left(\mathrm{Kg} / \mathrm{m}^{3}\right), \mathrm{Cg}$ the specific heat of the gas $\left(\mathrm{J} \mathrm{Kg}^{-1} \mathrm{~K}^{-1}\right)$ and $\eta_{\mathrm{g}}$ is the dynamic viscosity of the gas $\left(\mathrm{P}_{\mathrm{a}} \cdot \mathrm{s}\right)$.

The energy conservation equation in a droplet is described by Fuqian et al. in [14] as follows:

$$
-A_{s} h\left(T_{d}-T_{A}\right)-A_{s} \varepsilon S_{T}\left(T_{d}^{4}-T_{A}^{4}\right)=V_{d} \rho_{d} C_{p d} \frac{d T}{d t}
$$


Where $V_{d}\left(\mathrm{~m} \mathrm{~s}^{-1}\right)$ is the relative velocity of the droplet, $\rho_{d}\left(\mathrm{Kg} \mathrm{m}^{-3}\right)$ is the droplet density and $\mathrm{C}_{\mathrm{pd}}\left(\mathrm{J} \mathrm{Kg}^{-1} \mathrm{~K}^{-1}\right)$ is the droplet specific heat.

For centrifugal atomisation, Qc dominates, so that Qr is ignored in the subsequent analysis. Then, Zheng, et al. estimate the cooling rate from the previously equation as follows [15]:

$$
\frac{d T}{d t}=\frac{6 h\left(T_{d}-T_{A}\right)}{C_{p d} \rho_{d} d}
$$

Therefore, substituting typical conditions into equation (4), and assuming a maximum gas flowrate of $200 \mathrm{~L} \mathrm{~min}^{-1}$, theoretically the cooling rate is estimated about $10^{4}-10^{5} \mathrm{~K} \mathrm{~s}^{-1}$ for the equipment described in this work. Applying the same conditions to calculate the cooling rate for the conventional centrifugal atomisation process, the difference for both methods is in the order of $10^{3} \mathrm{~K} \mathrm{~s}^{-1}$.

Interrelationship between the atomisation parameters, such as disc velocity melt superheat, disc diameter, gas flowrate, and their influence on the solidification process, are complex interactions which are common in centrifugal atomisation process and make it difficult to accurately predict the cooling behaviour of particles. As a result, the numerical analysis described in this article tends to overestimate the magnitude of the cooling rate. First of all, to simplify the analysis, heat radiation is ignored. Second, various empirical equations are incorporated in the analysis. Third, the values of the physical parameters of the melt, gas and others, are not accurately known. Therefore, although an experimental validation of the cooling rate would be necessary, the numerical analysis helps to provide information to a reasonable degree. 


\section{Effects of processing parameters on cooling rate}

Figure 7 shows the influence of rotational speed on cooling rate with a constant gas flowrate of $200 \mathrm{~L} \mathrm{~min}^{-1}$, for rotational speeds ranging from $15000 \mathrm{rpm}$ to $35000 \mathrm{rpm}$. It was found that the cooling rate is affected by the rotational speed. A higher disc speed applies more centrifugal force on the melt and the initial velocity of the particle is higher, this resulting in higher values of cooling rate. This finding is consistent to those previously reported by other researches [16].

Figure 7. Influence of disc speed on cooling rate with a constant gas flowrate of $200 \mathrm{~L}$ $\min ^{-1}$.

Figure 8 shows that although the cooling rate increases with increasing disc speed, it mainly affected by the mean particle size. The cooling rate increases one order of magnitude for particle sizes $<20 \mu \mathrm{m}$. This can be explained in terms of energy content; as smaller particles have smaller values of convective heat transfer coefficient.

Figure 8. Influence of disc speed on cooling rate with a constant gas flowrate of $200 \mathrm{~L}$ $\min ^{-1}$ for different particle sizes.

On the contrary, figure 9 shows that at a constant disc speed of $35000 \mathrm{rpm}$, hybrid gas flowrates from 0 to $200 \mathrm{~L} \mathrm{~min}^{-1}$ have little effect on the cooling rates. When gas flowrates increase, the change in cooling rate is not evident for a specific particle size, but, as shown previously, it is enough to change the microstructure, which suggest that the effect of hybrid gas on cooling rate is not simple. It is also noted from figure 10 that for the same particle size the curve is flat, which illustrates the weak dependence of cooling rate on gas flowrate, but it confirms its strong function of particle size.

Figure 9. Influence of gas flowrate on cooling rate with a disc speed of $35000 \mathrm{rpm}$. 
Figure 10. Influence of gas flowrate on cooling rate with a disc speed of $35000 \mathrm{rpm}$ : (a) for different gas flowrates, (b) for different particle sizes.

With these experiments, it was found that even a small change in cooling rate can affect the final microstructure of the final powder. Thus, theoretically speaking, the powder microstructure can be controlled by cooling rate which enhances unique microstructures in attempts to produce powder of new alloys which hitherto have not been possible.

\section{CONCLUSION}

A new complementary hybrid system was constructed and applied to produce $\mathrm{Cu}$ powder. The effects of gas flowrate and rotating disc speed on the particle size distribution, microstructure and cooling rate were studied. The following conclusions could be drawn from the theoretical calculation and experimental results:

(1) Particle size distribution does not change with the hybrid complementary system but it has a strong relationship with the disc rotational speed. The particle size became finer with increasing disc speed.

(2) The particle grain size tends to decrease with the addition of the hybrid complementary system and with increasing the gas flowrates. At lower speeds of atomisation, the effect of the hybrid gas flowrate is stronger due to the extra velocity component.

(3) The cooling rate of the atomized particles increased with decreasing particle size, and it can reach more than $10^{5} \mathrm{~K} / \mathrm{s}$ for $<20 \mu \mathrm{m}$ powders. Based on the results and analysis, the cooling rate is strongly dependant on particle size and rotational speed and it has a weak dependence on gas flowrate used in this study. 


\section{ACKNOWLEDGEMENTS}

This work was supported by the Industrial Doctorate Plan of the Secretariat for

University and Research of the Department of Enterprise and Knowledge of the Generalitat of Catalonia under Grant 2019 DI-19.

\section{REFERENCES}

1. Singer ARE, Kisakurek SE. Centrifugal spray deposition aluminium strip. Met Technology. 1976;3:565-570.

2. Frost AR. Rotary atomization in the ligament formation mode. J Agric Engineering Res. 1981;26:63-78.

3. Klaphaak DJ, Barnes LG, inventor; Atomization System Inc., assignee. Method of centrifugal atomization. United States Patent. 3,720,737. 1973 March 13.

4. Yule AJ, Dunkley JJ. Atomization of melts. Oxford. Clarendon Press; 1994.

5. Lavernia J, Srivatsan TS. The rapid solidification processing of materials: science principles, technology advances and applications. J Mater Sci. 2010;45:287-325.

6. Yung-Zhong L, Minagawa K, Kakisawa H, et al. Melt film formation and disintegration during novel atomization process. Trans Nonferrous Met Soc China. 2007; 17:1276-1281.

7. Plookphol T, Wisutmethangoon S, Gonsrang, S. Influence of process parameters on SAC305 lead-free solder powder produced by centrifugal atomization. Powder Technology. 2001;214:506-512.

8. Malvern Panalytical Limited. Optimizing metal powders for additive manufacturing. Worcestershire: Technical documentation; 2018.

9. Minagawa K, Kasisawa H, Osawa Y, et al. Production of fine spherical lead-free solder powders by hybrid atomisation. 2005;6:325-329.

10. Sungkhaphaitoon $\mathrm{P}$, Wisutmethangoon S, Plookphol T. Influence of process parameters on zinc powder produced by centrifugal atomisation. Mater res. 2017;20(3):718-724.

11. Xie JW, Zhao YY, Dunkley JJ. Effects of processing conditions on powder particle size and morphology in centrifugal atomization of tin. Powder Metall. 2004;47(2):168-172.

12. Dantzig JA, Rappaz M. Solidification. Switzerland. EPFL Press; 2009. 
13. Zheng B, Yaojun L, Yizhang Z, et al. Gas atomization of amorphous aluminium powder: Part II. Experimental Investigation. Metall and Mater Trans B. 2009;40B:995-1004.

14. Fuqian Z, Ming X, Jianliang L, et al. Study of rapidly solidified atomization technique and production of metal alloy powders. Mater Science and Eng. 2001;A304-306:579-582.

15. Zheng B, Yaojun L, Yizhang Z, et al. Gas atomization of amorphous aluminium powder: Part I. Thermal behaviour calculations. Metall and Mater Trans B. 2009;40B:768-778.

16. Östürk S, Arslan F, Östürk B. Effect of production parameters on cooling rates of AA2014 alloy powders produced by water cooled, rotating disc atomisation. 2003;46(4):342-348. 
Table1 Processing experimental parameters of atomisation

\begin{tabular}{|c|c|}
\hline & $\begin{array}{l}\text { Pouring temperature of the melt }=1200^{\circ} \mathrm{C} \text {, graphite disc } \\
\text { diameter }=40 \mathrm{~mm} \text {; hybrid gas composition }=\text { Nitrogen, chamber } \\
\text { gas pressure }\left(\mathrm{N}_{2}\right)=0,7 \text { bar; melt flowrate } \sim 75 \mathrm{Kg} \mathrm{h}^{-1}\end{array}$ \\
\hline Disc speed (rpm) & Gas $\left(\mathrm{N}_{2}\right)$ flowrate $\left(\mathrm{L} \mathrm{min}^{-1}\right)$ \\
\hline 15000 & $0-100-200$ \\
\hline 25000 & $0-100-200$ \\
\hline 35000 & $0-100-200$ \\
\hline
\end{tabular}

